\title{
PAPER NUMBER
}

$$
\operatorname{con} F-830.445--54
$$

$$
\text { BNL-NUREG-32913 }
$$

\section{DISCLAIMER}

This report was prepared as an account of work sponsored by an agercy of the United States

DE83 012211 Government. Neither the United States Government nor any agency thereof, nor any of their employees, makes any warranty. express or implied, or assumes any legal liability or responsibilizy for the accuracy, completeness, or usefulness of any information, apparatus, product, or process disclosed, or represents that its use would not infringe privately owned rights. Reference nerein to any specific commercial product, process, or service by trade name, trademark, manufacturer, or otherwise does not necessarily constitute or imply its endorsement, recomnendation, or favoring by the United States Government or any agency thereof. The views and opinions of authors expressed herein do not necessarily state or reflect those of the United States Government or any agency thereof.

EFFECT OF THERMAI STABILIZATION ON THE LOW-TEMPERATURE STRESSCORROSION CRACXIAG OF INCONEL 600

\author{
R. Bandy and D. van Rooyen \\ Corrosion Science Group \\ Department of Ruc lear Energy \\ Brookhaven National Laboratory \\ Upton, NY 11973
}

\section{ABSTRACT}

The propensity to low-temperature stress-corrosion cracking (SCC) of thermally stabilized Inconel 600 in sulfur-bearing environments has been investigated using U-bends and slow-strain-rate testing. The results have been compared with those of sensitized Inconel 600 . The potential dependence of crack-propagation rate has been established in a single test by using several U-bends held at different potentials, by choosing an appropriate electrical circuitry. The difference in SCC susceptibility of the sensitized and stabilized materials has been discussed in terms of the grain-boundary chromium depletion and resulting intergranular attack in boiling ferric sulfate-sulfuric acid tests, and electrochemical potentiokinetic reactivation (EPR) tests.

\section{INTRODUCTION}

Sensitized Inconel 600 sufferg rapid stress corrosion cracking (SCC) at low temperature in sulfur bearing environments such as polythionic acid, sodium terrathionate and sodium thiosulfate. $1-5$ Scarberry et 31.1 reported maximum sensitization, i.e., maximum susceptibility to intergranular attack in nitric acid and SCC in polythionic acid when the alloy was exposed to times and temperatures near the boundaries of the precipitation region on the time-temperaturetransformation diagram resulting in continuous grain boundary carbides with continuous chromium depleted areas near the boundaries. Hcrever, treatment of the alloy to conditions we 11 within the precipitation region resulted in discontinuous grain boundary precipitation and replenishment of chromium deplefed arenem 
As a result, propensity to incergranular corrosion in nitric acid and SCC in polythionic acid reduced significantly.

SCC resistance in caustic is also improved significantly by a suitable thermal treatment in the carbide precipitation regime $6-10$ and the improvement has been correlated with the presence of a semi-continuous grain boundary precipitate.11 Such a thermal treatment also improves the SCC resistance in high temperature water.12,13 However, slow strain rate tests in high temperature water on thermally stabilized (as received $+700^{\circ} \mathrm{C}, 20 \mathrm{~h}$ ) specimens showed that although significant improvement in SCC resistance resulted from thermal stabilization, very shallow intergranular penetration was still observed on the surface of the specinen.13 Recently the grain boundary chromium depletion and the resulting intergranular corrosion and SCC behavior have been studied as a function of thermal treatment. 14,15 For optimum thermal condition, Airey 15 has suggested the following thermal treatment: $982-1010^{\circ} \mathrm{C}$ for 1 to 5 minutes, followed by $704^{\circ} \mathrm{C}$ for 15 hours. This heat treatment apparently provides the maximum resistance to SCC in caustic and also gives a relatively uniform condition of microstructure and mechanical properties and thus helps to overcome to a large extent the problem of dealing with the wide heat to heat variability of mill annealed materials. In this study, we have generally followed the above thermal treatment suggested by Airey.

In the present work we compare the SCC susceptibility of thermally stabilized Inconel 600 in polythionate enviroments, using both static and dynamic straining, with that of sensitized Inconel 600 that undergoes rapid SCC in this environment. Also, intergranular corrosion susceptibility of the stabiiized and sensitized materials are compared using boiling ferric sulfatesulfuric acid tests 16 and electrochemical potentiokinetic reactivation (EPR) tests.17, 18

\section{EXPERIMENTAL}

Tests were conducted on comercially produced nuclear grade Alloy 600 material. Two different heats with compositions shown in Table 1 were used. Most of the tests were ccnducted on the tubing material (heat No. 1, Table 1) outside diameter $22 \mathrm{~mm}$ and wall thickness $1.24 \mathrm{~mm}$. Some U-bend tests were performed with the $5 \mathrm{~mm}$ thick plate material (heat No. 2, Table 1). Heat No. 1 was sensitized to two different conditions - directly sensitized from the mill annealed condition (MAS), and solution annealed followed by sensitizing heat treatment (SAS). All heat treatments are described in detail in Table 2 . Heat No. 2 was sensitized to SAS condition only. For thermal stabilization (TS), both materials received the same heat treatment: $982^{\circ} \mathrm{C}$ for 4 minutes, rapidly cooled in air followed by $705^{\circ} \mathrm{C}$ for $16 \mathrm{~h}$.

Reverse U-bends were prepared frow the tubing material (heat No. 1) using procedures described elsewhere.13 The plate material (heat No. 2) was cut into approximately $100 \mathrm{~mm} \times 6 \mathrm{~mm}$ strips and formed into U-bends following ASTM standard G 30-72. All U-bend and slow strain rate tests were conducted in aerated solution of freshiy prepared $\mathrm{O}_{5} \mathrm{MM}$ sodium tetrathionate $\left(\mathrm{Na}_{2} \mathrm{~S}_{4} \mathrm{O}_{6}\right)$, following procedures described elsewhere. 4,5 
The U-bends prepared from the plate material were tested using a modification of the technique of Seys and Van taute 19 which allowed multiple specimens to be tested, each at a different potential, in a single test. This replaced their single wire specimen along which they created a potential gradient by means of an impressed current. In our test, several specimens were connected in series, separated by resistors of suitable predetermined values. The potential of one of the specimens was adjusted to a desired value by means of a potentio-stat. A relatively large direct current $(\sim 0.2 A)$ was passed from a power supply through the circuit, thus bringing the potential of each specimen to a different value as a result of the (iR) potential drop across each of the resistors. The potential of each specimen was measured with a Luggin probe calomel electrode combination. In the Seys and Van Haute technique, the resistance of the wire specimen was used to provide the iR drop.

For detecting susceptibility to intergranular attack, specimens of roughly 10 to $20 \mathrm{~cm}^{2}$ area each were tested for 24 haurs in a boiling solution of ferric sulfate and sulfuric acid following the appropriate ASTM standard. I6 In each test, only a single specimen was used.

EPR tests were performed on $1 \mathrm{~cm}^{2}$ coupons polished to $600 \mathrm{grit}$, in $0.5 \mathrm{M}$ $\mathrm{H}_{2} \mathrm{SO}_{4}+0.01 \mathrm{M}$ KSCN solution. The thod consisted of holding the specimen at $+0.4 \mathrm{~V}$ vs. SCE for 4 minutes and then polarizing it to -0.20 vs. SCE at a scan rate of $1 \mathrm{mV} / \mathrm{S}$. A PAR Modal 350 Corrosion Measurement System was used which automatically computed the amount of charge accumulated during the polarization.

\section{RESULTS AND DISCUSSION}

Potential-time Behavior of U-bends

The variation of corrosion potential with time of MAS and TS reverse Ubends (heat No. 1 ) in $0.1 M$ sodium tetrathionate solution is shown in Figure 1 . In both cases, the potential shifted to the negative direction within a few seconds of imersion, and then slowly drifted towards the positive direction. However, unlike the MAS specimen, the TS one had a sharp transition to positive potential within a few hours. The potential monitoring was discontinued after about 50 hours, except for occasional checks of the potential of the TS specimen which continued to move slowly in the positive direction and reached +312 in vs. SCE in 150 hours. The MAS specimen suffered through wall cracking within about 5 to 5 hours of immersion, whereas the TS specimen did not crack in 800 hours. The potential excursions in Fig. 1 are perhaps indications of film formation and zrowth on the specimen surfaces and it is apparent that the two specimen surfaces behaved very differently, owing perhaps to different film composition on them. Also, the potential of the sensitized (MAS) specimen could have stayed low because of active grain boundary corrosion. It is evident from the above results that the SCC resistance of TS specimen to polythionate cracking improves significantly by the TS treatment.

\section{Multiple U-bends Under Rotential Control}

Figure 2 shows the relationship between electrochemical potential and crack propagation rate of SAS U-bends of heat Ho. 2 material. An initial $20 \mathrm{~h}$ 
test caused throughwall eracks in several specimens in the potential range where the propagation rate is very high. Therefore, a second test was conducted for about 7 hours at those potentials. After the test, each specimen surface was polised and examined under the microscope and the crack propagation rate was determined by dividing the maximum crack length by the total test duration and thus, it includes the initiation time involved in each case. Therefore, the net propagation race will be higher in aach case than that shown in Fig. 2 . In addition, several tests were conducted using a single specimen ach time, held potentiostatically at a particular potential and the results were essentially similar to those in Fig. 2. The results show that the SAS material cracks very rapidly in $0.1 \mathrm{M}$ tetrathionate over wide range of potential. The specimen at $+500 \mathrm{mV}$ did not crack but suffered intergranular attack (IGA), as shown in Fig. 3 .

Five TS U-bends, using heat No. 2 were also tested simultaneously in $0.1 \mathrm{M}$ ceirathionate solution within the potential band of -293 to $+165 \mathrm{mV}$ SCE. The test was continued for 100 hours without any cracks on any of the specimens.

The multiple specinen tests under potential control appears to be a very elegant method of ScC tesing where susceptibility over a wide range of potential can be deterained in a single test. The wethod has been applied successfully in SCC testing in high temperature enviroments and is currently being used for examining caustic cracking of Alloy 600.20

\section{Slow Strain Rate Testing}

Four TS specinens tested with stain rates of 1,2 and $5 \times 10^{-6} / \mathrm{s}$ and $10^{-5} / \mathrm{s}$ in $0.1 \mathrm{M}$ tetrathionate showed almost identical ultimate tensile stress (UTS) and \% elongation to failure and these values were similar to those for a TS specimen tested in the laboratory air at $10^{-5}$ /s (Table 3). However, the specimens tested in the environment at 1 and $2 \times 10^{-6} / \mathrm{s}$ showed a fer extremely shallow intergranular penetratious on the faces of the specimens (Fig. 4). The specinens underwent considerable amount of necking and the SEM fractograph exhibited completely ductile behavior (Fig. 5).

Another specimen was held in 0.1M tetrathionate solution on a MTS servohydraulic machine under stroke control at an initial nominal stress of 262 $\mathrm{MPa}$, i.e., $\sim$ yield strength of the material. The load relaxed owing to initial creep to about $236 \mathrm{MPa}$ (nominal) within the first two days, but subsequently held relatively steady. After four weeks, the solution was replaced with a fresh batch and the specimen was strained to failure at a strain rate of $10^{-6} / \mathrm{s}$. The results (specimen 3 , Table 3 ) indicate some reduction in 7 elongation and a slight reduction in UTS compared to those strained in $0.1 M$ tetrathionate imediately after immersion, or in laboratory air. However, the fractograph of specimen 3 was completely ductile. The reduction in 7 elongation or UTS in specimen 3 was probably due to some pitting that slowly occurred during the four weeks of exposure of the specimen in the tetrathionate solution and is not related to any intergranular penetration. The U-bends, tensile specimens and separate coupons of the TS material suffered localized deteriorations on the surface within a few weeks of immersion in the tetrathionate environment, as shown typically in Fig. 6 (a) for a TS coupon immersed in $0.1 M$ tetrathionate solution for two weeks. 
There were some minute pits which grew larger with time, as illustrated in Fig. 6(b) for the same specinen examined eight weeks after imersion. It should be pointed out, however, that Inconel 600 would suffer some localized attack under any thermal condition in the severe environment tested. However, from the SCC standpoint, these pits did not lead to any premature failure of the TS specimen, as observed from the results on specimen 3 (Table 3). The SAS specimen, however, when tested as above, i.e., held for a few weeks on the MTS machine and then slowly strained, suffered severe SCC with a $z$ elongation and UTS of 67 and $253 \mathrm{MPa}$ respectively, and an average crack propagation rate of $50 \mathrm{~mm} / \mathrm{s}$, based on the maximum crack length and the total time of the slow strain rate test.

Susceptibility to Intergranular Attack

\section{Ferric Sulfate - Sulfuric Acid Test}

The results of $24 \mathrm{~h}$ tests in boiling solutions of the above environment Eor mill annealed (MA), MAS, SAS and TS materiais of heat No. 1 are sumarized in Table 4. Evidently, the sensitizing heat treatments increased the susceptibility to intergranular attack significantly, the effect of SAS treatment being much more severe than the MAs one. Clearly, the TS treatment reduced the susceptibility to intergranular attack substantially, the weight loss being smaller by about a factor of 3.5 than that for the materia?. All four specimens were bent in a vice $\left(s 30\right.$ to $\left.45^{\circ}\right)$ after the tests and the resulting SEM micrographs (Figs. $7(\mathrm{a})$ to (c)) for the MA, MS and TS specimens respectively show that all of them suffered cracking as a result of the bending. The SAS specimen almost disincegrated in the environment, as was also noticed by Theus 21 for this type of material in this enviroment. Lacking any appreciable grain boundary strength, the SAS material became very soft and deformed readily when bent and gave a ductile appearance in the SEM micrograph, Fig. 7(d). The major implication of the above tests is that the TS macerial, in spite of significant improvement in weight loss in the ferric sulfate-sulfuric acid environment, still shows some suscepiibility to intergranular attack.

\section{EPK Tests}

The results of the EPR tests, expressed as the integral charge value normalized to the grain boundary area are shown as $P_{a}\left(\mathrm{c} / \mathrm{cm}^{2}\right)^{17}$ in Table 4 for the MA, MAS, SAS and TS materials of heat No. 1, where,

$$
P_{a}\left(C / \mathrm{cm}^{2}\right)=\frac{Q}{G B A}
$$

and

$Q=$ charge measured during the polarization scan,

$$
G B A=A_{S}\left(5.09544 \times 10^{-3} \exp (0.34696 x)\right)
$$

$A_{s}$ and $X$ being the specimen area and ASTM grain size at a magnification of 100 respectively. It is clear from the $P_{a}$ values in Table 4 that the EPR tests 
make goed distinction between the HAS and SAS specimens; but the difference between the MA and TS specimens is small. Sensitization increases the potential range for active dissolution during the reverge scan, as can be seen from the polarization curves in Fig. 8 for the four heats tested, and thus accounts for the higher $P_{a}$ values for the sensitized specimens. In sensitized stainless steel, EPR tests apparently saturate at higher levels of sensitization, causing a loss of discriminating power. 22 However, this aspect of sensitization of Iconel 600 was not studied by us.

The relatively large $P_{a}$ values reported in Table 4 for all four heats are due to the comparatively slower scan rate ( $1 \mathrm{mV} / \mathrm{s})$ used in our tests, compared to those generally used for sensitized stainless steels.17,22 However, for a comparative evaluation of the four heats, the scan rate chosen should not influence the results. Future work will involve examining the effects of scan rate, and also of environments containing uuch lower concentrations of KSCN which apfarently provide better separation of results in Iconel 600.23

Sensitized Iconel 600 seems to give a much larger $P_{a}$ value compared to that of sensitized 304 stainless steel. For example, SAS 304 stainless steel which also suffers rapid cracking in the tetrathionate environment, gave a $P_{a}$ value of $109.5 \mathrm{C} / \mathrm{cm}^{2}$ after the $\mathrm{EPR}$ test in $0.5 \mathrm{M} \mathrm{B}_{2} \mathrm{SO}_{4}+0.01 \mathrm{M} \mathrm{RSCN}$ at a scan rate of $1 \mathrm{mV} / \mathrm{S}$, compared to a $\mathrm{P}_{\mathrm{a}}$ value of $774.3 \mathrm{c} / \mathrm{cm}^{2}$ for SAS Inconel 600 (Table 4). The higher $P_{a}$ value for Inconel 600 is manly due to two factors: (a) carbon solubility in Inconel 600 is wuch less than in 304 stainless steel and hence Inconel 600 is amenable to more severe sensitization, and (b) owing to the lower chromium contert of Inconel 600 , its matrix is generally attacked much more than in the 304 stainless steel by the environment during the EPR test. The high $\boldsymbol{P}_{a}$ value of $133.2 \mathrm{c} / \mathrm{cm}^{2}$ for the TS specimen in our EPR test is perhaps due to the second factor.

Figures 9 (a) to (d) illustrate the optical micrographs for the MA, MAS, SAS and TS specimens after the EPR tests. Clearly both MAS and SAS specimens were significantly attacked, with the grain boundary grooves in the SAS being somewhat more continuous than those in the MAS material. The MA specimen also appears to be slightly attacked, while the nature of atcack on the TS material remains rather unclear. SEM micrographs on the four specimens, especially the $M A$ and $T S$ ones did not provide any additional information.

\section{Transmission Electron Microscopy}

In order to follow the grain boundary carbide precipitation, thin foils of the MA, MAS, SAS and TS materials wre examined under the transmission electron microscope. The MA material appears to have some grain boundary areas free from any carbide precipitation, Fig. $10(\mathrm{a})$, and some areas with relatively large inter and intra granular carbide precipitates, Fig. 10(b). The MAS and SAS treatments cause much more continuous carbide precipitation along the boundaries, Figs. $10(c)$ and (d) respectively, the width of the precipitates being much larger in the SAS material. The TS treatment gives rise to semicontinuous carbide precipitates, Fig. 10(e), as was also observed by others.14,24 No attempt was made to obtain a quantitative evaluation of chromium depletion or segregation of other elements such as phosphorus and sulfur as 
a result of the various hear ereatments. However, Airey mentions 15,24 that for the TS heat treatment chosen in this study, chrowium re-diffusion generally becomes complete in about 10 hours at $705^{\circ} \mathrm{C}$.

\section{COLCLUSIONS}

(1) The TS treatment significantly improves the resistance to polythionate SCC of Alioy 600 in both static and dynamir straining tests.

(2) The potential dependence of crack propagation rate has been established in a single static test holding several U-bends at different potentials, using a modification of the Seys and Van Haute technique.

(3) Weight loss results of boiling ferric sulfate-sulfuric acid tests give a reliable quantitative correlation of the susceptibility to intergranular attack resulting from sensitizing or stabilizing heat treatments.

(4) Results of EPR tests seem to be confirmative for sensitized specimens, but rather inconclusive for the TS material.

\section{ACKNOWLEDGEMENT}

This work was supported by the U. S. Department of Energy, Division of Basic Energy Sciences, under Contract No. DE-ACO2-CH00016 and the U. S. Nuclear Regulatory Commission under FIN A-3208. 
1. Scarberry, R.C., Pearman, S.C., Crum, J.R. Corrosion 32, 401 (1976).

2. Berge, Ph., Donati, J.R. Nuclear TechnologY, 55, 88 (1981).

3. Newman, R.C, Roberge, R. and Bandy, R. ASTM Proc. Conf.: "Environmentsensitive Fracture: Evaluation and Comparison of Test Methods", Gaithersburg, Maryland, In Press (1982).

4. Bandy, R., Roberge, R, Nemman, R.C. Corrosion, submitted for publication.

5. Bandy, R., Roberge, R., Newman, R.C. Corrosion Science, submitted for publication.

6. Pessal1, N., Airey, G.P., Lingenfelter, B.P. Corrosion, 35, 100 (1979).

7. Airey, G.P., Corrosion, 35, 129 (1979).

8. Berge, Ph., Donati, J.R., Prieux, B., Villard, D. Corrosion, 33, 425 $(1977)$.

9. Theus, G.J. Huclear Technology, 28, 388 (1976).

10. Airey, G.P. Corrosion, 36, 9 (1980).

11. Airey, G.P. Metallography, 13, 21 (1980).

12. Domain, H., Emanuelson, R.H., Katz, L., Sarver, L.H., Theus, G.J. Corrosion, 33, $26(1977)$.

13. Bulischeck, T.S., VanRooyen, D. Corrosion, 37, 597 (1980).

14. Was, G.S., Tischner, H.H., Latanision, R.M. Meta11. Trans. 12A, 1397 (1981).

15. Airey, G.P. EPRI Report No. NP-2093, October (1981).

16. ASTM Standard G28-72, Fart 10, Annual Book of ASTM Standards (1980).

17. Clarke, W.L. Cowan, R.I., Halker, W.L. Intergranular Corrosion of Stainless Alloys, ASTM STP 656, P. 99, R.F. Steigerwald, ed. Philadelphia (1978).

13. Cowan, R.L., Tedmon, C.S. Jr. "Intergranular Corrosion of Iron-NickelChromium Alloys", in Advances in Corrosion Science and Technology, Vol. 3, ed. Fontana, M.G., Staehle, R.W., Plenum Press, New York (1973).

19. Seys, A.A. Van Haute, A.A. Corrosion, 29, 329 (1973). 
20. Van Rooyen, D. unpublished data.

21. Theus, G.J., Corrosion, 20 (1977).

22. Mignone, A., Bore110, A., LaBarbera, A. Corrosion, 38, 390 (1982).

23. Clarke, W.L, General Electric Co., Pleasanton, Calif. Private communication.

24. Airey, G.P. "Optimization of Metallurgical Variables to Improve the Stress Corrosion Resistance of Inconel 600", EPRI Report. No. NP-1354, March $(1980)$. 


\section{TABLE 1}

Chemical Composition (wt.\%) of Alloy 600 Tubing and Plate

\begin{tabular}{lccccccccccc}
\hline Heat No. & Cr & Se & C & Cu & Si & Al & Ti & Mn & Co & S & Ni \\
\hline 1 (Tubing) & 14.62 & 9.41 & 0.04 & 0.40 & 0.32 & 0.29 & 0.22 & 0.17 & 0.02 & 0.001 & balance \\
2 (Rlate) & 14.57 & 9.04 & 0.05 & 0.29 & 0.07 & & & 0.25 & & 0.004 & balance \\
\hline
\end{tabular}

\section{TABLE 2}

Heat Treatment and Symbols Used

$$
\begin{aligned}
& \text { MA - Mil1 annealed (As received) } \\
& \text { MAS - MA }+621^{\circ} \mathrm{C}, 18 \mathrm{~h} \\
& \text { SAS - } 1135^{\circ} \mathrm{C}, 45 \text { min., water quenched }+621^{\circ} \mathrm{C}, 18 \mathrm{~h} \\
& \text { TS }-928^{\circ} \mathrm{C}, 4 \text { min., rapidly air cooled }+705^{\circ} \mathrm{C}, 16 \mathrm{~h}
\end{aligned}
$$


TABLE 3

Results of Slow Strain Rate Tests on TS Specimeas

in 0.1M Tetrathionate Solution*

\begin{tabular}{cccc} 
Specimen No.* & Strain Rate & $\begin{array}{c}\text { Elongation } \\
\text { to } \begin{array}{c}\text { Eailure } \\
1\end{array}\end{array}$ & UTS, MFa \\
\hline 2 & $10^{-5 / \mathrm{s}}$ & 46 & 640 \\
3 & $10^{-6 / \mathrm{s}}$ & 44 & 640 \\
& $10^{-6 / \mathrm{s}}$ & 36 & 617
\end{tabular}

*Specimen 1 was tested in laboratory air, 2 in 0.1 tetrathionate solution, immediately after imersion, 3 was held in $0.1 \mathrm{M}$ tetrathionate solution on a MTS machine under stroke control at an initial nominal stress of 262 MPa for 4 weeks and then slowly strained at $10^{-6} / \mathrm{s}$ in a fresh solution of $0.1 M$ tetrathionate. 
TABLE 4

Results of Ferric Sulfate-Sulfuric Acid Test and

ERR Tests on Four Different Specimen Types

Weight Loss in

Ferric Sulfzca-Sulfuric

Acid lest, $\mathrm{mon} / \mathrm{y}$
Pa Values From
EPR Tests, $\mathrm{C} / \mathrm{cm}^{2}$

111.3

209.4

774.3

133.2

TS

1.29 


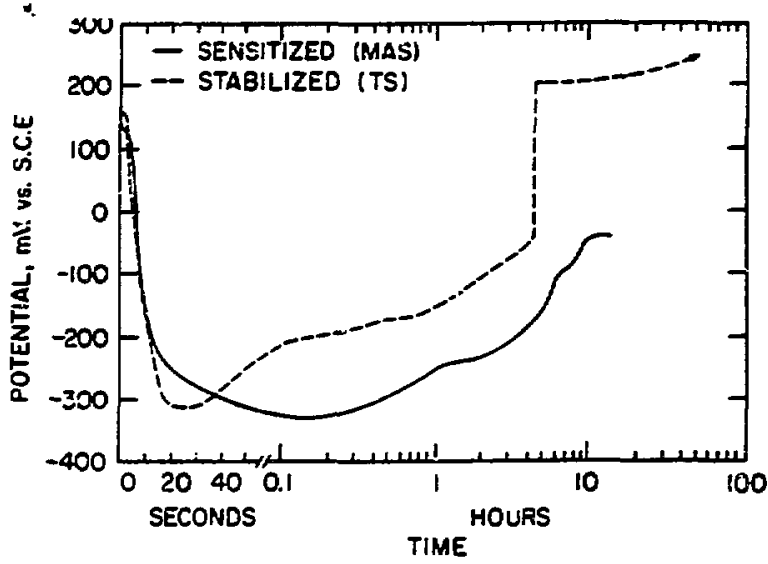

Fig. 1. Potential-time behaviour of v-bends of sensitized (MAS) and thermally stabilized (TS) Inconel 600 in $0.1 \mathrm{M}$ sodium tetrathionate solution.

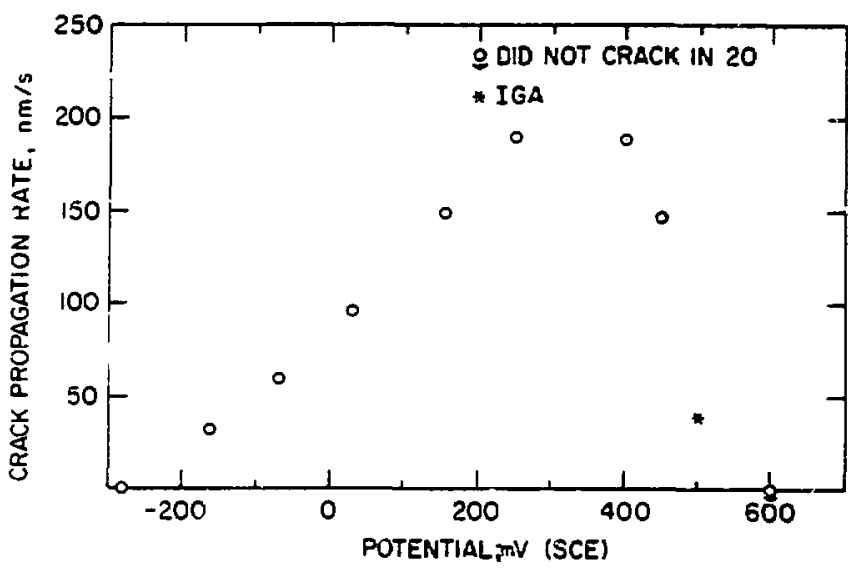

Fig. 2. Relationship between potential and crack propagation rate of sensitized (SAS) Inconel 600 in $0.1 \mathrm{M}$ tetrathionate solution. Specimens were multiple $U$-bends held at different potentials.

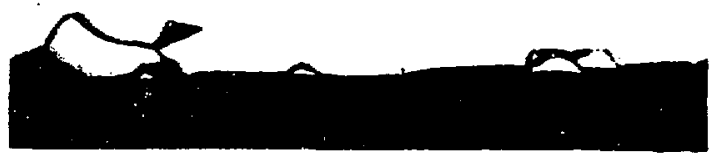

Fig. 3. Intergranular attack on sensitized (SAS) Inconel $600 \mathrm{U}$-bend held it +500 mV vs. SCE in $0.1 M$ tetrathionate

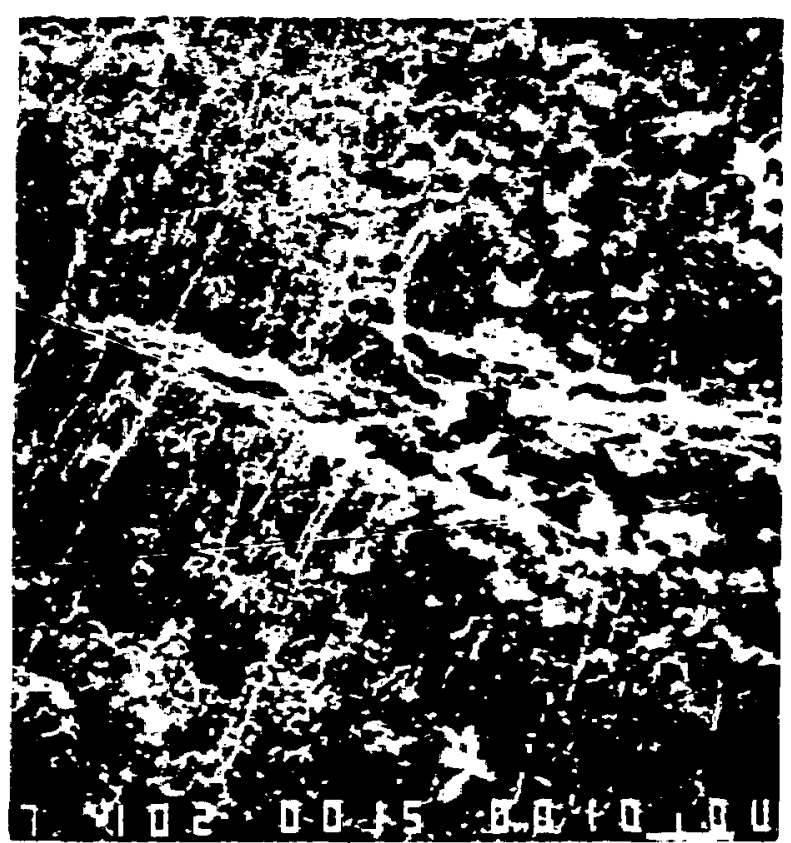

Fig. 4. Shallow intergranular peretration on the face of tensile specimen of stabilized (TS) Inconel 600 tested at a strain rate of $10^{-6 / s}$ in $0.1 \mathrm{Y}$ tetrathionate solution. $1000 x$

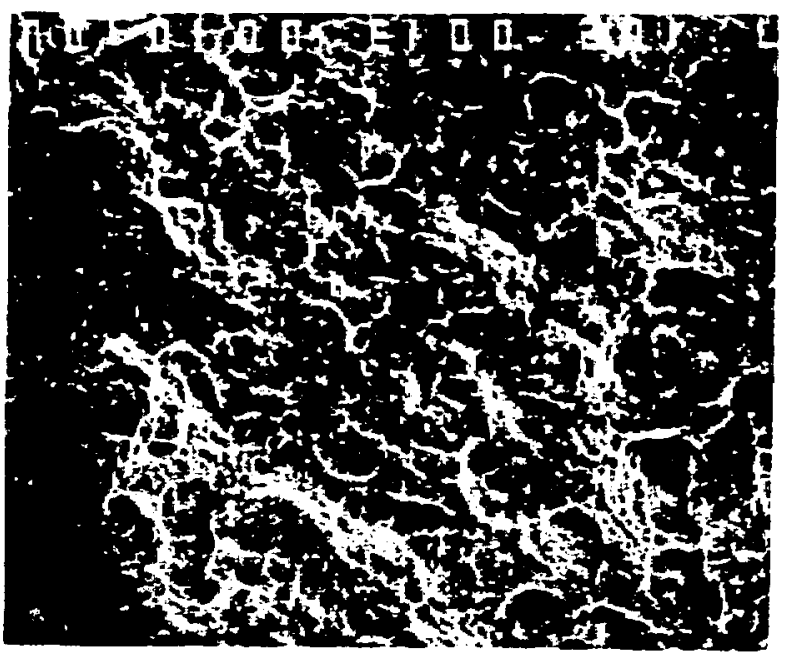

Fig. 5. Typical SEM fractograph of stabilized (TS) Inconel 600 tensile specimen after slow strain rate test in $0.1 M$ tetrathionate solution. $1000 \mathrm{x}$ 


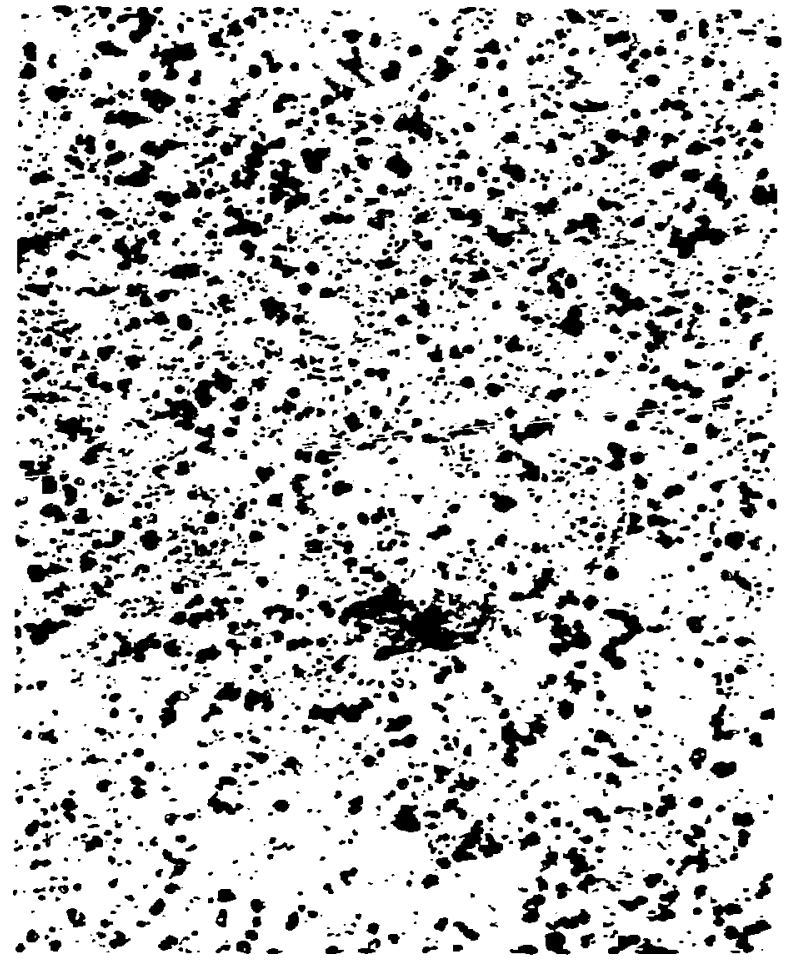

Fig. 6(a). Localized attack on a

scabilized (TS) Inconel 600 coupon

immersed for 2 weeks in $0.1 \mathrm{M}$ tetrathionate solution. $100 x$

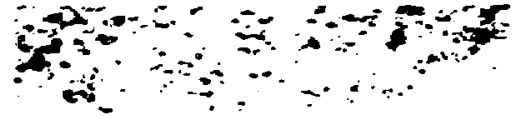

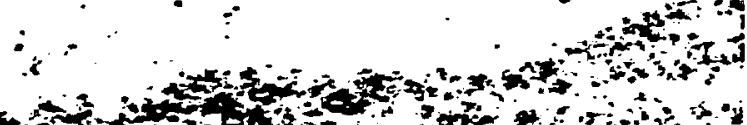
I0

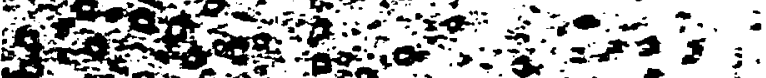

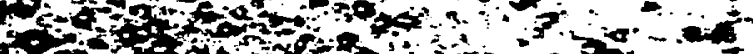

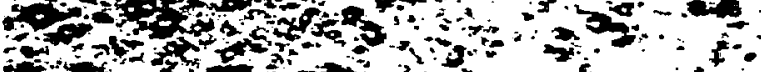

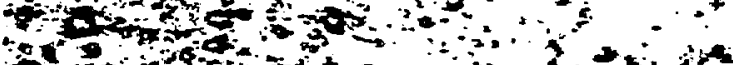

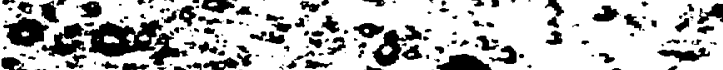

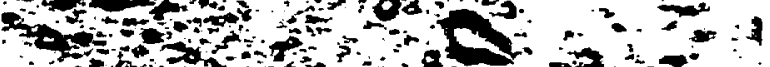

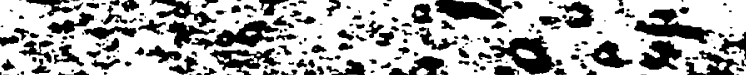

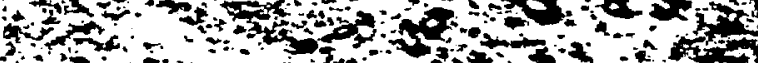

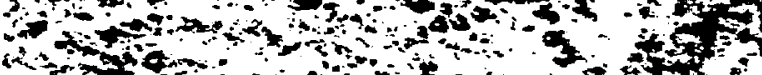

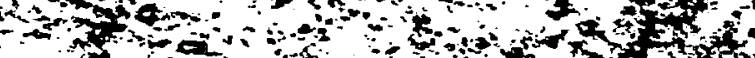
Now

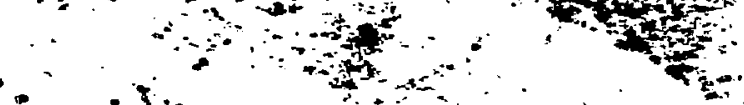
$=-1$.

Fig. 6(b). Pitting on the same specimen as in Figure 6 (a) after 8 weeks. $100 x$

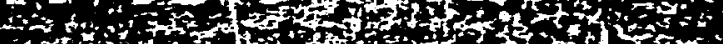
3.

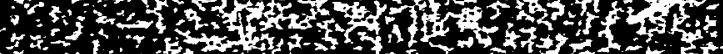
-

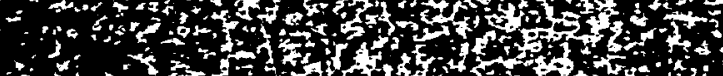
$\rightarrow$ a (1)

Fig. 7(a). SEM micrograph ố a mill annealed Inconel 600 specimen tested in boiling ferric sulfate and sulfuric acid and bent after the test. 100x

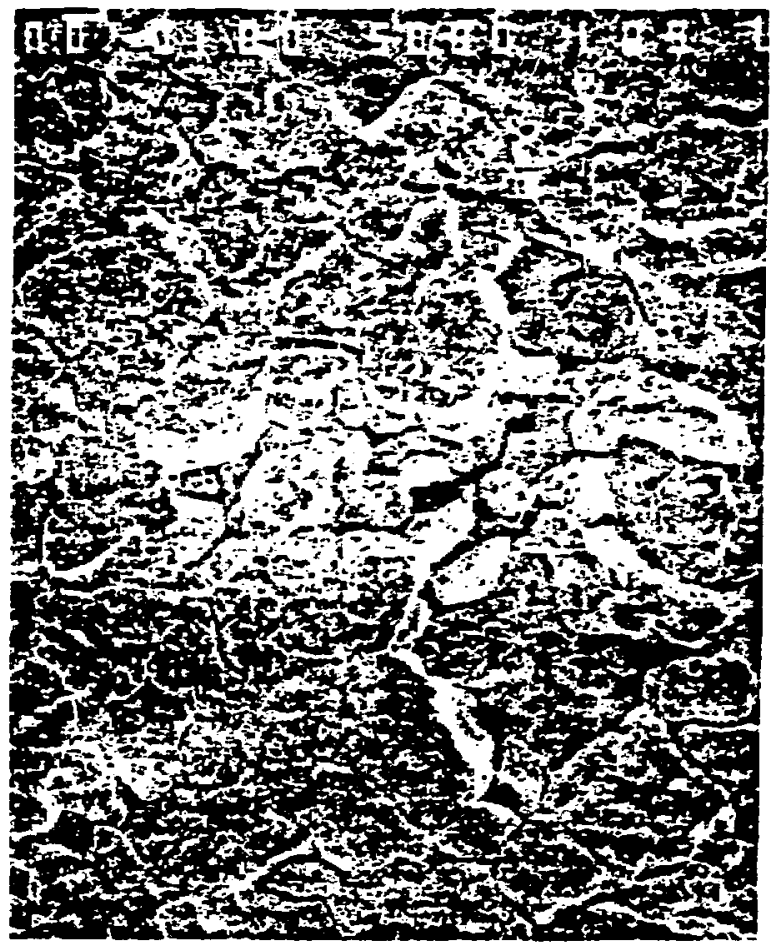

Fig. 7 (b). Sane test as in Fig. 7(a) on a mill annealed and sensitized (MAS) Inconel 600 specimen. 500x 


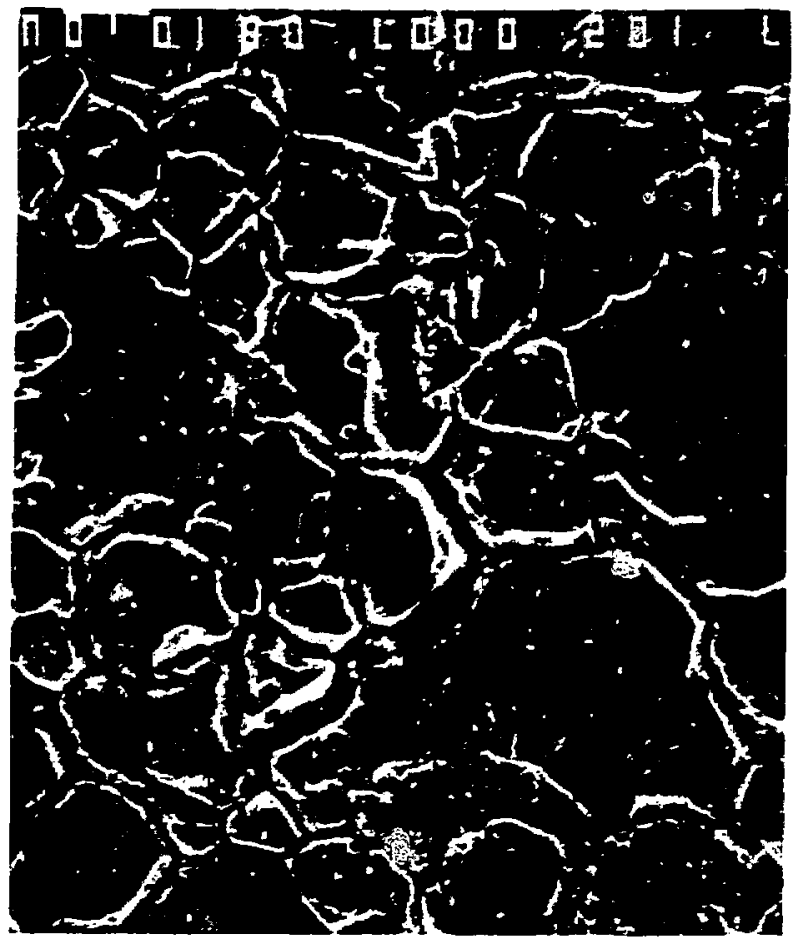

Fig. $7(c)$. Same test as in Fig. $7(3)$ on a stabilized (TS) Inconel 600 specimen. $1000 \mathrm{x}$

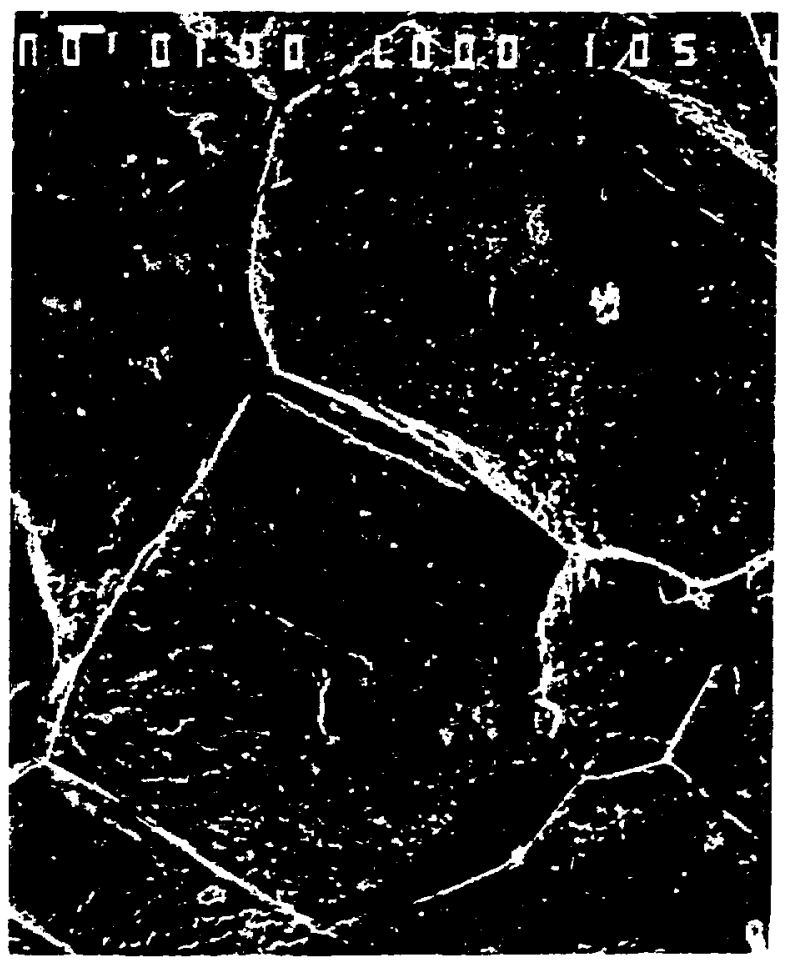

F1g. 7 (d). Same test as in Fig. 7(a) on a solution annealed and sensitized (SAS) Inconel 600 spectmen. 500x

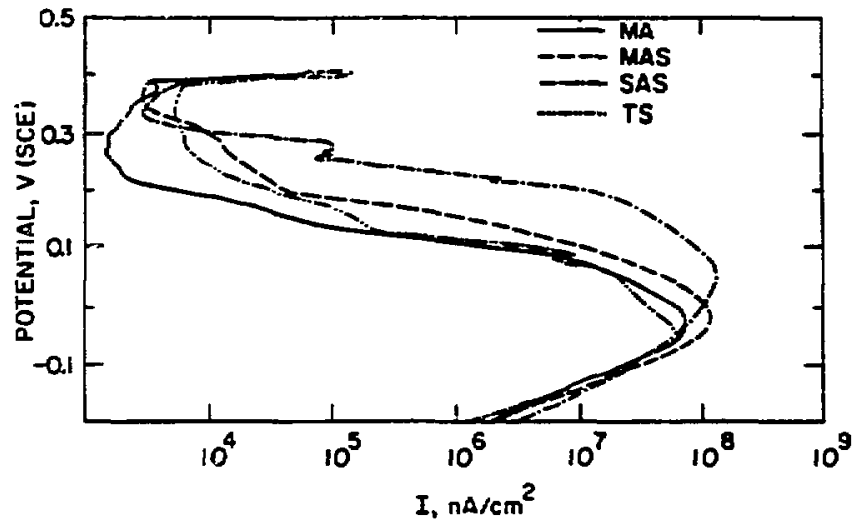

Fig. 8. Reverse scan polarization test (EPR) on Incone1 600 under four different thermal conditions in $0.5 \mathrm{M}$ $\mathrm{H}_{2} \mathrm{SO}_{4}+0.01 \mathrm{KSCN}$ solution at a scan rate of $1 \mathrm{mV} / \mathrm{s}$.

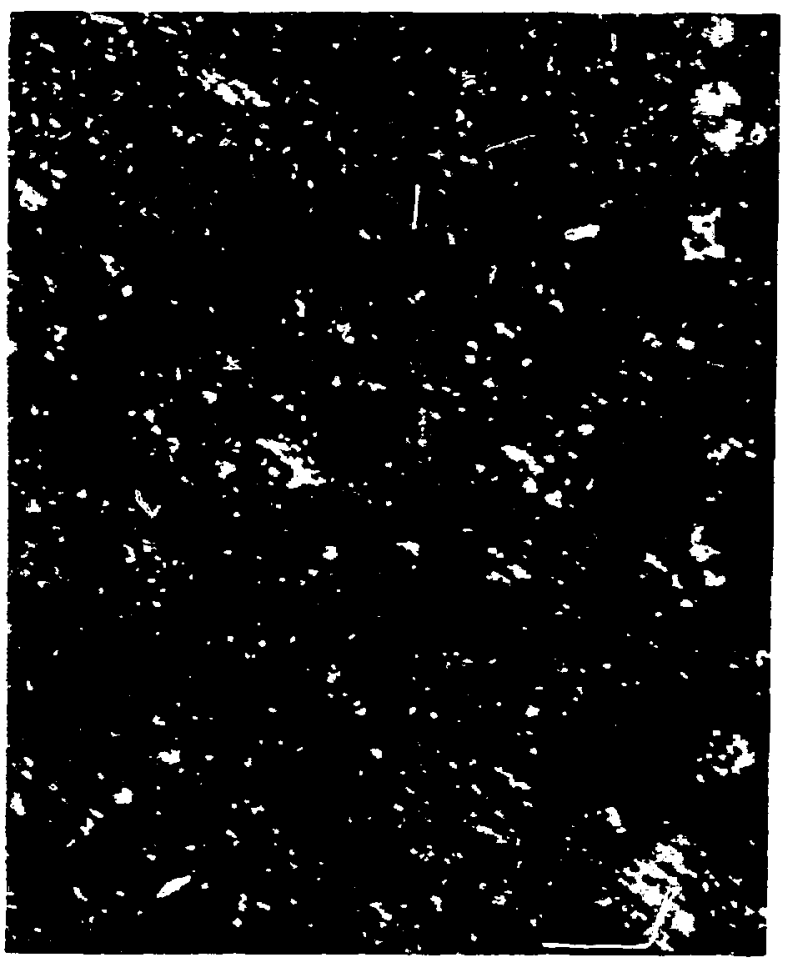

Fig. 9(a). Optical micrograph of a mill annealed (MA) specimen after EPR test. $400 x$ 


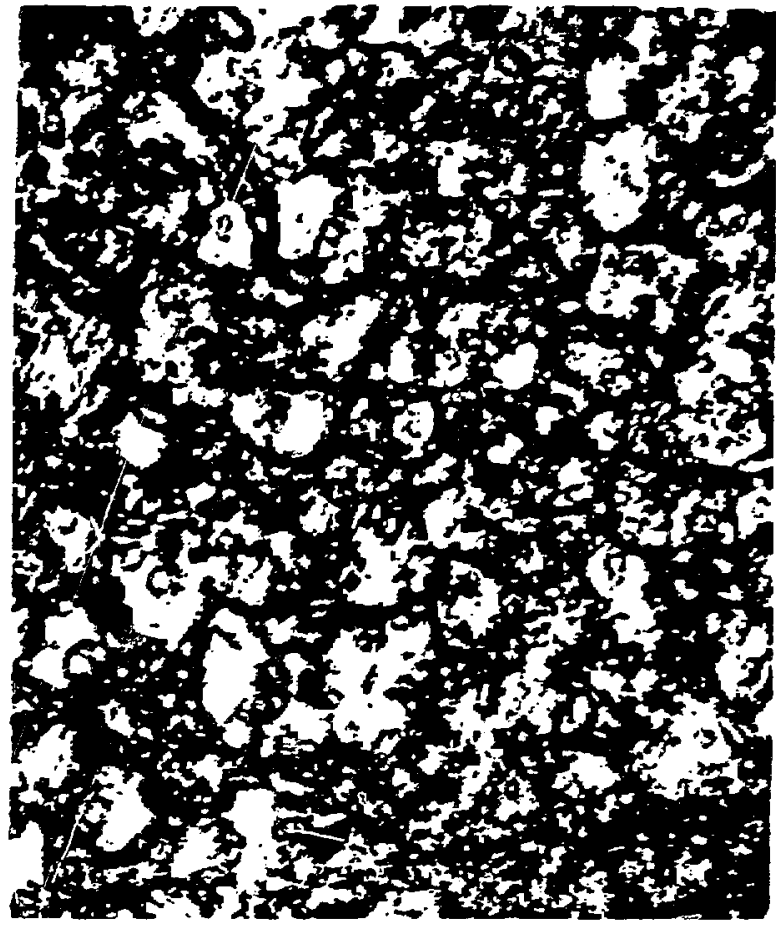

Fig. 9(b). Optical micrograph of a mill annealed and sensitized (MAS) specimen after EPR test. 400x

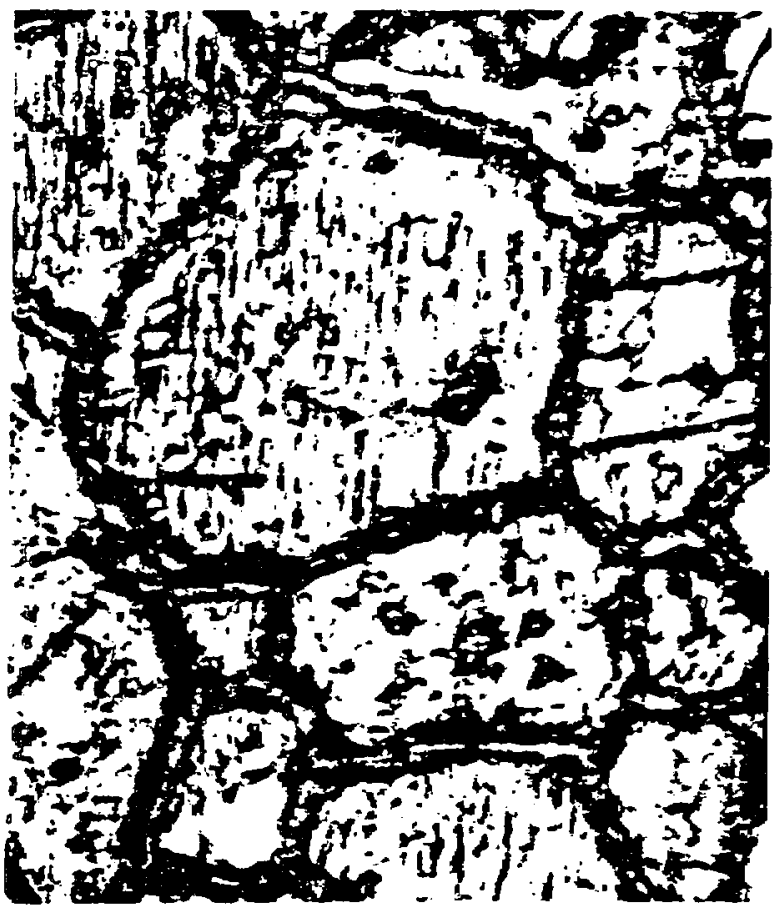

Fig. 9(c). Optical micrograph of a solution annealed and sensitized (SAS) specimen after EPR test. $400 x$

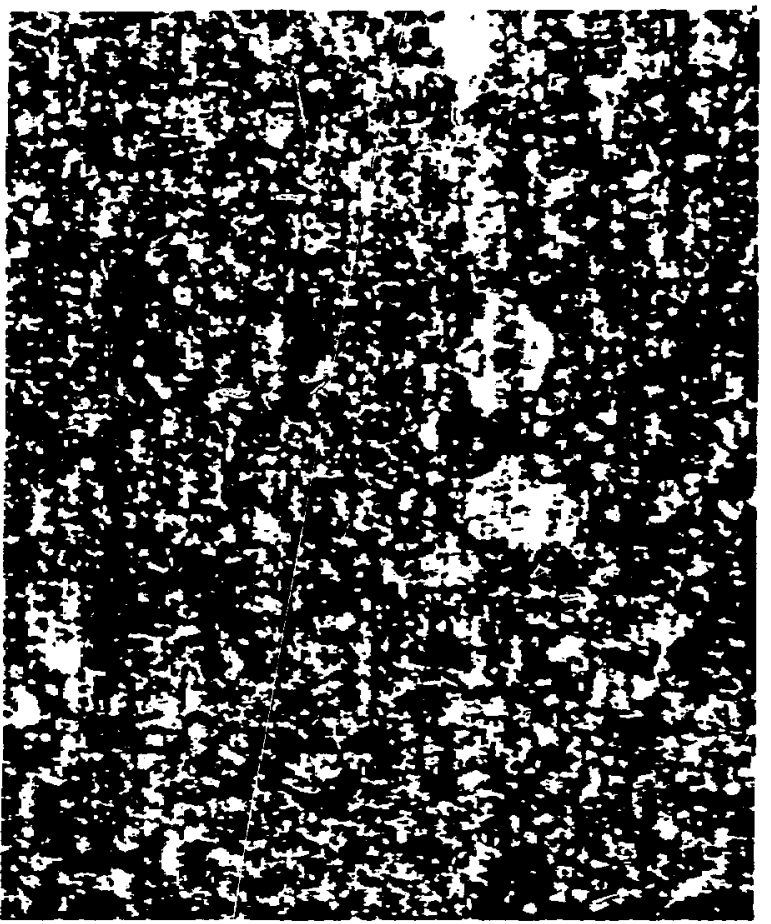

Fig. $9(d)$. Optical micrograph of a stabilized (TS) specimen after EPR test. $400 x$

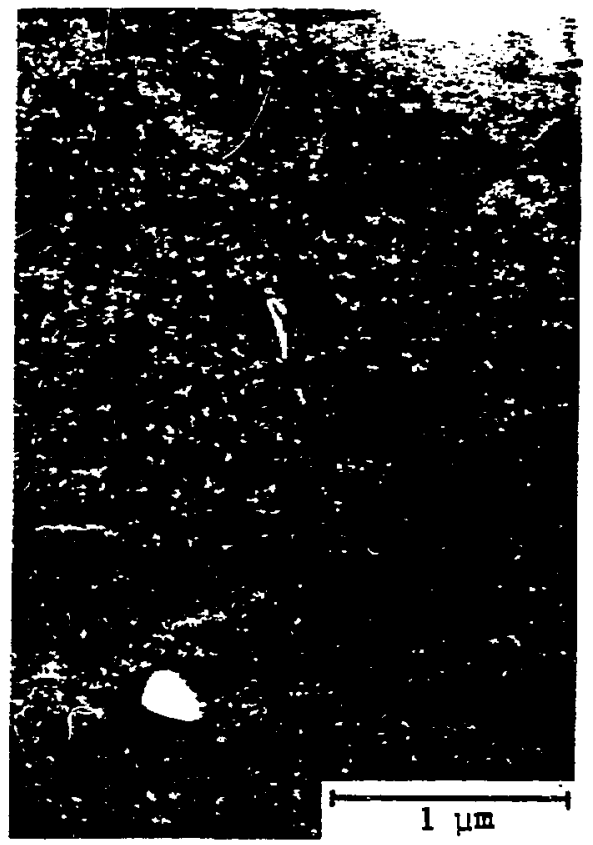

Fig. 10(a). Transmission electron micrograph (TEY) of a mill annealed (MA) specimen showing relatively clean grain boundary areas. 


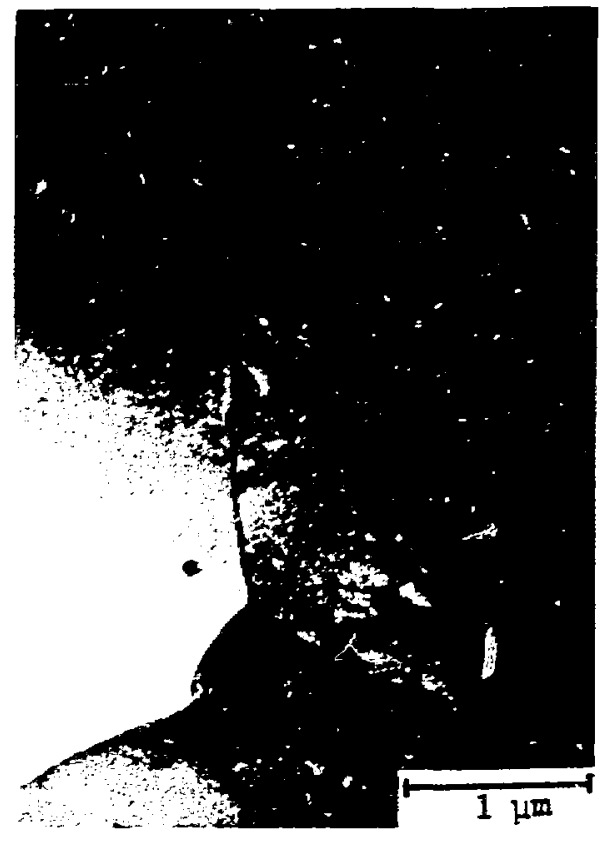

Fig. 10(b). TEM of a mill annealed specimen (MA) showing inter and intra granular precipitates.

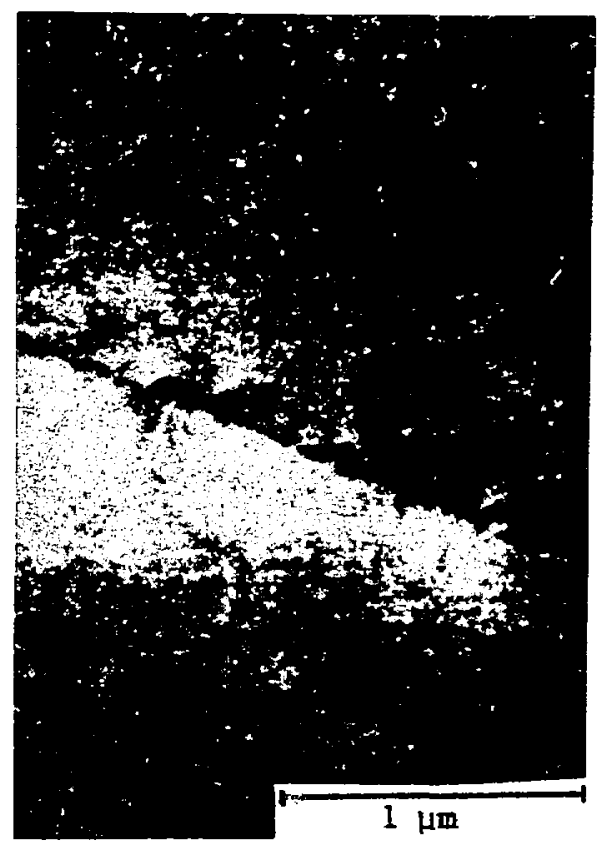

Fig. 10(c). TEM of a mill annealed and sensitized (MAS) specimen showing relatively fine but continuous grair. boundary precipitates.

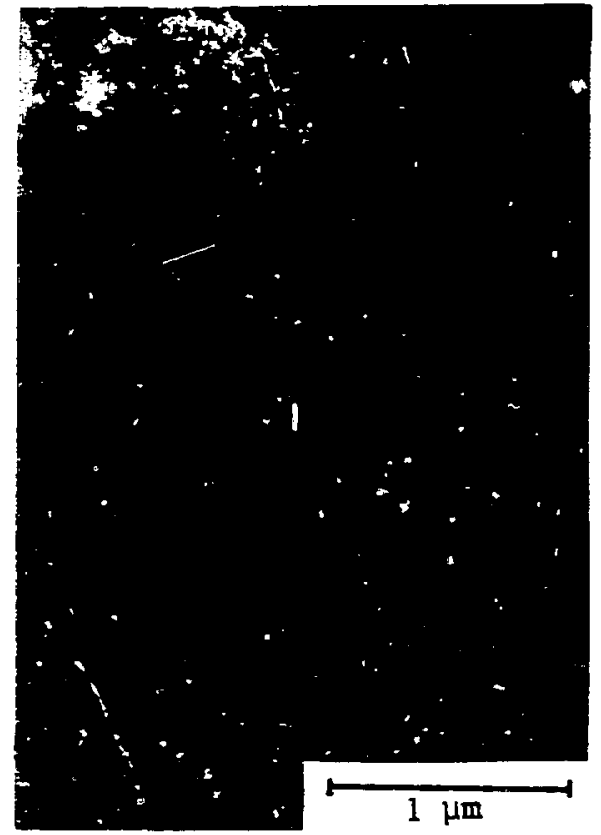

Fig. 10(d). TEM of a soiution annealed and sensitized specimen (SAS) showing heavy continuous grain boundary precipitates.

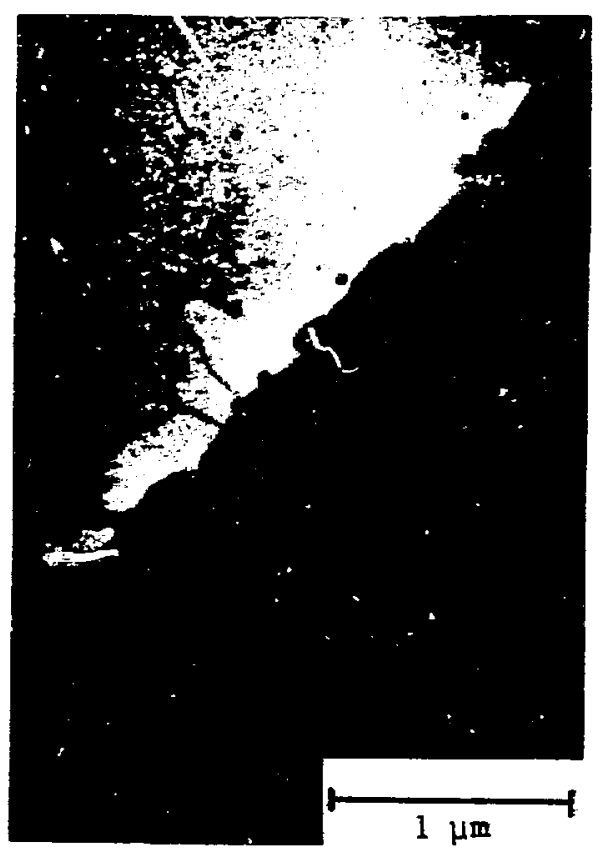

Fig. 10(e). TEM of a thermally stabilized (TS) specimen showing semi-continuous grain boundary precipitates. 